\title{
LOS DERECHOS SOCIOLABORALES COMO DERECHOS HUMANOS: AFIRMACIÓN, RECONOCIMIENTO Y ÓBICES A SU EXIGIBILIDAD EN EL ORDENAMIENTO JURÍDICO BRASILEÑO
}

\author{
SOCIAL AND LABOUR RIGHTS AS HUMAN RIGHTS: AFFIRMATION, \\ RECOGNITION AND OBSTACLES TO THEIR ENFORCEABILITY INTO THE \\ BRAZILIAN LEGAL SYSTEM
}

Marcio Morena Pinto*

\begin{abstract}
RESUMEN
El presente artículo tiene como finalidad reflexionar acerca de los obstáculos existentes a la plena exigibilidad de los derechos humanos sociales de forma en general en el ordenamiento jurídico brasileño, con especial destaque a los derechos laborales. El enfoque de la investigación asienta sus bases en la premisa de que la dignidad de la persona humana es el principio rector de toda la normativa jurídica internacional y nacional sobre el trabajo. En este sentido, es cierto que la Constitución de la República Federativa de Brasil de 1988 consolidó esa idea, reconociendo un verdadero núcleo duro de derechos laborales para el alcance de un nivel mínimo protección que garantizara al obrero la supradicha dignidad. Por consiguiente, se impone al Estado la búsqueda efectiva por la materialización de ese mínimo de condiciones que le permitan al trabajador alcanzar un nivel de vida digno. Por lo tanto, como se examinará a lo largo del presente artículo, las justificaciones jurídicas que han sido formuladas en el ámbito del Poder Judicial para obstaculizar el pleno alcance de su exigibilidad deben ser consideradas ilegítimas frente a la imperiosa previsión constitucional de su reconocimiento y a la transcendencia del principio de la dignidad humana en el ordenamiento jurídico brasileño.
\end{abstract}

\section{PALABRAS-CLAVE}

Derechos humanos. Derechos laborales. Dignidad. Exigibilidad. Trabajo.

\begin{abstract}
This article aims to reflect about the obstacles to the full enforcement of social human rights in the Brazilian legal system, with special emphasis on labor rights. The research approach rests on the premise bases that the dignity of the human person is the guiding principle of international and national legal regulations about labor. In this sense, it is true that the Constitution of the Federative Republic of Brazil, from 1988, consolidated this idea, recognizing a true hard core of labor rights for achieving a minimum level protection to guarantee dignity for the workers. Therefore, the State is obliged to effectively search the materialization of that minimum conditions that enable workers to achieve a decent standard of living. Therefore, as it will be examined throughout this article, legal justifications that have been made in the field of the Judiciary to impede the full scope of its enforcement should be considered illegitimate, because of the manifested constitutional provision of

\footnotetext{
* Doutor em Direito Internacional pela Universidade de Barcelona (Espanha). Mestre e bacharel em Filosofia pela Faculdade de Filosofia, Letras e Ciências Humanas da Universidade de São Paulo (FFLCH-USP). Máster em Estudos Internacionais pela Universidade de Barcelona (Espanha). Professor universitário e de cursos preparatórios para carreiras públicas. Autor de livros e artigos nas áreas de Direito Internacional, Filosofia Política e Relações Internacionais. Advogado (São Paulo, SP, Brasil).E-mail: marciomorena@hotmail.com
} 
its recognition and the transcendence significance of the principle of human dignity in the Brazilian legal system.

\section{KEYWORDS}

Human rights. Labor rights. Dignity. Enforcement. Labor.

\section{INTRODUCCIÓN}

El trabajo es toda acción humana realizada con gasto de energía física o mental, acompañada o no del auxilio de instrumentos, pero siempre dirigida a un fin determinado que no es otro sino producir efectos en el propio agente que la realiza, transformando el mundo (MARTINS FILHO, 2009, p. 3). Como señala Rieznik (2004, p. 21), el trabajo es considerado una acción a propósito, guiada por la inteligencia, constituyéndose en un producto especial de la humanidad.

Es por medio de su actividad laboral que el hombre "fabrica la interminable variedad de cosas cuya suma total constituye el artificio humano”, como afirmó Arendt (1993, p. 157). En esta perspectiva, los hombres no pueden tener un precio, es decir, no pueden ser utilizados únicamente como simples instrumentos para la producción de bienes por ningún otro hombre; ni siquiera por sí mismo. Eso porque el individuo es un fin en sí mismo, y en esto consiste precisamente su dignidad humana, en virtud de la cual se elevan todas las cosas (KANT, 2007, p. 47-48).

Dworkin (1998, p. 305) definió la dignidad humana como el derecho del hombre a vivir en condiciones bajo las cuales sea posible el autorespeto, o sea, en un contexto sociocultural de existencia tal que le permitiera ser tratado de manera inclusiva en su comunidad. De ahí que ciertos derechos mínimos pasaron a cobrar relieve para que se alcanzaran efectivamente esas condiciones sociales, pasándose a exigir una actitud proactiva de los Estados para garantizarlos.

La dignidad humana se reviste de dos dimensiones axiológicas: libertad e igualdad. Como señala Monereo Atienza (2005, p. 271-272), todos los derechos humanos tienen dimensiones de libertad e igualdad, aunque la fundamentación de cada uno se base en una extensión diferente de esos valores. Por consiguiente, si por un lado la libertad formal y la igualdad ante la ley serían típicas de los derechos civiles y políticos, por otro, la libertad real, entendida como capacidad, y la igualdad material, como punto de llegada, serían peculiares de los derechos sociales.

En el ámbito específico de los derechos sociolaborales, reflexiona Bonet Pérez (1999, p. 5) que la dignidad humana en el trabajo debe tener la garantía efectiva de la libertad, lo que significa que quien ostenta la condición de trabajador, como ser humano que es, debe poder ejercer su actividad laboral de manera libre y con respeto de su propia personalidad y de sus derechos como individuo.

De ahí surgen dos implicaciones muy importantes de esa constatación: la primera es la 
proyección de la dignidad humana en la dimensión laboral de su existencia; y la segunda, es la interrelación de esos derechos sociolaborales fundamentales con la libertad misma del trabajador como ser humano, en cuanto manifestación de los derechos del individuo y de su libertad personal en este ámbito particular.

No obstante el respeto a la libertad sea la condición inherente al ejercicio del trabajo, es en la igualdad que se asienta, a menudo, el derecho laboral. La igualdad es el fin último justificador de su existencia (PÉREZ LUÑO, 2009, p. 42), puesto que las relaciones jurídicas entre dos clases sociales económicamente antagónicas se equilibran por medio de ella: una que posee la propiedad de los bienes de producción y que tiene recursos económicos, y otra frecuentemente caracterizada por tener escasas propiedades y medios económicos muy precarios, dependiendo de la primera.

Sentado que la dignidad es el punto común entre todos los seres humanos, y que, por esa razón, debe legitimar y justificar la garantía de determinados derechos considerados esenciales con vistas a garantizar un mínimo de condiciones, especialmente en el ámbito laboral, es cierto que el principio de la dignidad de la persona humana debe transcender toda normativa que se refiera a derechos humanos sociolaborales, en ámbito nacional e internacional.

Al hilo de lo señalado, se puede afirmar que la propia historia del derecho sociolaboral asienta sus bases en el reconocimiento de la dignidad humana. Como se sabe, esa rama del derecho se originó durante la Revolución Industrial, en el siglo XVIII, a partir de una imperiosa necesidad de la sociedad de poner fin a un régimen laboral cada vez más drástico y que afrontaba directamente la dignidad humana. La explotación del trabajador era nítida y perceptible a través de las condiciones subhumanas en que la labor era desarrollada (largas jornadas de labor, prácticamente ininterrumpidas; locales mal alambrados y sin higiene; pagamentos muy bajos, etc.).

A pesar de la cuestionable igualdad formal que caracterizaba el pacto realizado entre empleador y empleado, desde un punto de vista material la desigualdad era tremenda. El obrero se veía obligado a la contratación laboral bajo condiciones miserables, justamente porque su condición social y económica no le dejaba otra alternativa para ganar su sustento. Como señala Geremek (1998, p. 251), la masa de la población obrera era tratada como un espacio social de la indigencia.

Es cierto que las más serias consecuencias generadas por la industrialización fueron innegablemente sociales (HOBSBAWM, 1995, p. 64). La transición de la nueva economía creó gran miseria y descontentamiento, dos ingredientes que contribuirían para la revolución social que sería llevada a cabo por los trabajadores de la industria y las poblaciones pobres de las ciudades, culminando en las Revoluciones de 1848 en el continente europeo y en los amplios movimientos cartistas en Inglaterra. 
El derecho laboral surgió, entonces, como una urgente respuesta del Estado para proteger a los trabajadores y asegurar su dignidad humana, garantizando, a la vez, la continuidad del sistema capitalista por medio de un control del mercado y de una regulación de la utilización empresarial del trabajo (LOPEZ, 2004, p. 110). En este sentido, señala Burgoa (2002, p. 704) que, al establecerse garantías sociales, se formó una relación de derecho entre los grupos sociales favorecidos (las castas situadas en bonancible posición económica), y aquellos frente a los que se implantó la tutela (las clases sociales carentes del poder económico o de los medios de producción).

Como analiza Pérez (2007, p. 164-165), la relevancia de los derechos humanos sociolaborales puede ser ponderada desde las perspectivas axiológica, jurídica y económica. Así que, bajo la óptica axiológica, esos derechos vinieron a expresar en el ámbito material los valores y objetivos básicos secundados por la sociedad internacional, considerando que la dignidad humana se encuentra en el centro de esos valores, por lo que proyectan, en teoría, una perspectiva axiológica universal.

A su vez, a través de una perspectiva jurídica, el fundamento parece situarse en su categorización como principios y valores fundamentales; y, desde la perspectiva económica, la garantía de los derechos sociolaborales fundamentales responde a la racionalidad económica del funcionamiento eficaz del aparato productivo estatal, ya que se prohíben ciertas prácticas abusivas inhumanas y que cercenan la libertad en el mercado de trabajo.

De ahí que la dignidad humana debe servir de fundamento último para el reconocimiento del derecho laboral como un derecho humano y, a la vez, justificar su carácter universal y consecuente exigibilidad jurídica, al final, la dignidad es el punto común de existencia entre todos los trabajadores, y su preservación es lo que debe legitimar y justificar la garantía de determinados derechos mínimos al trabajador.

Así pues, el Estado, por conducto de las autoridades que al efecto establece la ley, debe velar por el cumplimiento de todas las modalidades jurídicas y económicas de la relación de derecho en que se ostentan las prerrogativas sociales (BURGOA, 2002, p. 706). Por tanto, no parece razonable que pueda admitir restricciones a su plena efectividad y, por cierto, exigibilidad, precisamente porque se asienta sobre la dignidad de la persona humana.

\section{EL DERECHO LABORAL COMO UN DERECHO HUMANO SOCIAL DE CARÁCTER UNIVERSAL}

Bobbio (1992, p. 5) ya señaló que los derechos humanos son derechos históricos, es decir, nacen gradualmente y no todos de una vez. Tampoco duran para siempre, sino que se imponen en 
determinadas circunstancias caracterizadas por luchas por la defensa de nuevas libertades contra viejos poderes. En este mismo sentido, subrayó Sachs (1998, p. 156) que los derechos humanos se conquistan, muchas veces con barricadas, en un proceso histórico lleno de vicisitudes, por medio del cual las necesidades y las aspiraciones se articulan en reivindicaciones y en estandartes de lucha antes que se les reconozca como derechos.

De acuerdo con Luño (2003, p. 48), los derechos humanos forman un verdadero “conjunto de facultades e instituciones que, en cada momento histórico, concretan las exigencias de la dignidad e igualdad humanas, las cuales deben ser reconocidas positivamente por los ordenamientos jurídicos a nivel nacional e internacional”. Otro no es el pensamiento de Flores (2000, p. IV), para quien los derechos humanos van más allá del conjunto de declaraciones y pactos que conforman el entramado jurídico-institucional, pues son "el conjunto de procesos normativos, institucionales y sociales que abren y consolidan espacios de lucha”.

A lo largo de los años, los avances jurídicos en la esfera de la protección jurídica del trabajador han sido muchos, y se deben, en gran parte, a la normativa internacional que se ha desarrollado en el seno de la Organización Internacional del Trabajo (OIT), consolidando una “categoría especial de derechos humanos”, como lo nombra Valticos (1998, p. 155), reconociendo un catálogo de garantías y derechos obligatorios de cuño universal al trabajador que le proporcione lo mínimo de dignidad en la consecución de su labor.

La OIT ha atribuido especial importancia a algunos derechos humanos sociolaborales que, en la práctica, se encuentran intrínsecamente vinculados con la dignidad humana en el ámbito de la vida laboral y, por ello, han adquirido una esencialidad que justifica, incluso, toda su acción normativa en pro de la mejoría de la situación de vida de los trabajadores en todo el mundo.

Aun cuando, paradójicamente, la OIT no emplea de manera formal y expresa el concepto jurídico de derechos humanos en su Constitución, es posible inferir esa naturaleza jurídica de los derechos laborales a partir de su propio objetivo que es esencialmente humanitario: establecer una reglamentación internacional susceptible de mejorar las penosas condiciones de trabajo impuestas por la dinámica productiva derivada de la Revolución Industrial (OIT, 2010, p. 5).

Para mejor compresión de lo señalado, son de gran lucidez las consideraciones de Pérez (1998, p. 21-22) cuando destaca que la aproximación conceptual y jurídica de la OIT a los derechos humanos se justifica precisamente en la necesaria interconexión entre la dignidad humana y la efectiva consecución de los objetivos en materia de justicia social de la Organización, tal y como se desprende de su Constitución y de la Declaración de Filadelfia, de 1944: “la priorización de ciertos derechos sociolaborales no hace nada más que subrayar que la preservación de la dignidad humana 
en el ámbito laboral es esencial en la actividad de la OIT”.

Dicha aproximación particular y específica se proyecta no sólo en los trabajos desarrollados en el seno de la propia OIT, sino también en los vínculos institucionales con otras Organizaciones internacionales, especialmente la Organización de las Naciones Unidas (ONU), destacándose aquí el acuerdo de vinculación de 1946, que reconoció la OIT como un organismo especializado competente para emprender la acción que considere apropiada, de conformidad con su instrumento constitutivo básico, para el cumplimiento de los propósitos expuestos en ellos (ONU, 1947, p. 24).

Dentro de la fase que se refiere al período de 1919 hasta 1978 de la trayectoria evolutiva del derecho laboral es que fueron producidos los más importantes instrumentos de protección internacional de esos derechos. La idea era imponer a la sociedad internacional el reconocimiento de un verdadero núcleo duro de derechos sociolaborales para alcanzar un nivel protección internacional de "mínimos", siempre que este nivel no existiera todavía en el ámbito interno de actuación de los Estados.

La Declaración Universal de los Derechos Humanos (DUDH) y el Pacto de Derechos Económicos, Sociales y Culturales (PIDESC) fueron los instrumentos responsables por la cristalización de ese núcleo duro fuera del ámbito de la OIT, imbuidos del espíritu del célebre discurso proferido en 1941 por el ex-presidente de los Estados Unidos, Franklin Roosevelt que, en su momento, destacaba, entre otros puntos, la importancia de que el Estado ofreciera una seguridad que permitiese al trabajador vivir exento de miedos en relación a las fuerzas económicas que le eran infinitamente superiores.

De todos los instrumentos internacionales de protección de los derechos humanos, el más significativo, no solamente en la historia del desarrollo de la positivización de los derechos de protección al trabajador, sino que, de todos los derechos humanos, es, sin duda, la DUDH, adoptada y proclamada en la Resolución 217 A (III) de la Asamblea General de las Naciones Unidas, de 10 de diciembre de 1948.

El texto retoma varias de las disposiciones que consagraron la filosofía social que había sido proclamada en la Declaración de Filadelfia, pasando a ser acogido como inspiración y orientación del proceso de desarrollo humano y social de toda la comunidad internacional, constituyéndose en un ímpeto decisivo para el proceso de generalización de la protección de los derechos humanos, permaneciendo, hasta hoy, como fuente de inspiración y punto de irradiación y convergencia de los instrumentos de derechos humanos en ámbito global y regional (TRINDADE, 1991, p. 1).

Con la Declaración de 1948, tuvo inicio una fase en la cual la afirmación de los derechos pasa a ser, al mismo tiempo, universal y positivizada. Universal en el sentido de que los destinatarios 
de los principios en ella convertidos no son más solamente los ciudadanos de este o aquél país, pero toda la humanidad, y positivizada porque pone en movimiento un proceso que objetiva que los derechos humanos no sean simplemente proclamados o solamente reconocidos en el plano teórico, sino también efectivamente protegidos, hasta mismo en contra del propio Estado que los haya violado.

Como señalan Sohn y Buergenthal (1973, p. 516), la Declaración se distinguió de las tradicionales cartas de derechos humanos de los siglos XVIII y XIX y comienzos del siglo XX que traían diversas normas fundamentales y constitucionales, en la medida en que no consagraba solamente derechos civiles y políticos, sino que también derechos económicos, sociales y culturales, como el derecho del trabajo

Como analiza Piovesan (2012, p. 46-47), al conjugar el valor de la libertad con el valor de la igualdad, la Declaración definió una nueva concepción de derechos humanos, concebidos, a partir de entonces, como una unidad interdependiente, interrelacional e indivisible:

[...] sem a efetividade dos direitos econômicos, sociais e culturais, os direitos civis e políticos se reduzem a meras categorias formais, enquanto que, sem a realização dos direitos civis e políticos, ou seja, sem a efetividade da liberdade entendida em seu mais amplo sentido, os direitos econômicos, sociais e culturais carecem de verdadeira significação. Não há mais como cogitar da liberdade divorciada da justiça social, como também infrutífero pensar na justiça social divorciada da liberdade. Em suma, todos os direitos humanos constituem um complexo integral, único e indivisível, em que os diferentes direitos estão necessariamente inter-relacionados e são interdependentes entre si.

La DUDH, como subraya Trindade (1999, p. 26), contribuyó decisivamente para la incidencia de la dimensión de los derechos humanos tanto en el ámbito internacional como en lo del derecho interno, vislumbrándose una abstracción de la fragmentación tradicional entre esos dos ordenamientos jurídicos, lo que promovió una constante interacción en beneficio de todos los seres humanos por fuerza de las disposiciones de los tratados de derechos humanos.

Es interesante notar que la DUDH, a pesar de no haber sido adoptada por un acto jurídico vinculante, se estableció como uno de los parámetros fundamentales utilizados por la sociedad internacional para deslegitimar cualquier actuación gubernamental de un Estado que vulnerase la normativa establecida en su seno. Así que, al menos teóricamente, si un Estado es violador de derechos humanos, no deberá ser merecedor de la aprobación por los demás Estados, como señala Cassesse (1990, p. 46-47).

En 16 de diciembre de 1966, la Asamblea General de la ONU, en su Resolución 2200 A (XXI), adoptó el ya señalado PIDESC, que reconoció en su artículo $7^{\circ}$ el derecho de toda persona al goce de condiciones de trabajo equitativas y satisfactorias que le aseguren en especial, una remuneración que proporcione, como mínimo, un salario equitativo e igual por trabajo de igual valor (sin distinciones de ninguna especie), asegurando a las mujeres condiciones de trabajo no inferiores 
a las de los hombres (con salario igual por trabajo igual), y condiciones de existencia dignas para ellos y para sus familias.

El mismo artículo buscó garantizar la seguridad y la higiene en el trabajo; igual oportunidad para todos de ser promovidos a una categoría superior (sin más consideraciones que los factores de tiempo de servicio y capacidad); el descanso, el disfrute del tiempo libre, la limitación razonable de las horas de trabajo; y las variaciones periódicas pagadas, así como la remuneración de los días festivos. Asimismo, el artículo $8^{\circ}$ trató del comprometimiento que los Estados Partes deberían tener en garantizar un conjunto mínimo de normas jurídicas que regularan el derecho colectivo del trabajo.

Hay que destacar en el PIDESC el derecho a la libre fundación de sindicatos y de afiliación, con sujeción únicamente a los estatutos de la organización correspondiente, para promover y proteger sus intereses económicos y sociales. De este modo, no se podrían imponer otras restricciones al ejercicio de ese derecho que las que prescriba la ley, y desde que sean necesarias, en una sociedad democrática, para proteger el interés de la seguridad nacional o el orden público, o para la protección de los derechos y libertades ajenos.

Tratando aún del derecho sindical, el PIDESC previó el derecho de los sindicatos a formar federaciones o confederaciones nacionales, y de éstas a fundar organizaciones sindicales internacionales o a afiliarse a las mismas, bien como de funcionar sin obstáculos y sin otras limitaciones, a la excepción de las señaladas en el párrafo anterior.

El derecho de huelga vino igualmente tratado en ya referido artículo $8^{\circ}$, trayendo de antemano la limitación a su ejercicio de conformidad con las leyes de cada país y la advertencia de que dicho artículo no impedirá someter a restricciones legales el ejercicio de tales derechos por los miembros de las fuerzas armadas, de la policía o de la administración del Estado, garantizándose, de esta manera, el pleno ejercicio de la soberanía a todos los que vendrían a firmarlo e incorporarlo a sus ordenamientos jurídicos internos.

En 10 de diciembre de 2008, por medio de la Resolución A/RES/63/117, fue finalmente adoptado el Protocolo Facultativo del PIDESC, que entró en vigor el 5 de mayo de 2013 proporcionando mecanismos de exigibilidad y acceso a medios de reparación (un procedimiento que busca justicia y compensación) para las violaciones de los derechos económicos, sociales y culturales.

No obstante todo lo anteriormente dispuesto en el sentido de la legitimación internacional del derecho laboral como un derecho humano de cuño social, muchos siguen siendo los obstáculos para esos derechos se tornen exigibles en el ámbito interno de los Estados.

La problemática de la cuestión gira en torno a la postura de algunos Estados que simplemente se niegan a ratificar tratados internacionales de derechos humanos, al paso que otros que lo hacen, 
pero, al momento de internalizarlos, les asignan un estatus infraconstitucional, lo que les permite no implementarlos en el caso de la promulgación de ley posterior que sea incompatible o, aún, lo más grave, llegan a ratificarlos e incorporarlos a su ordenamiento interno, pero no los tornan efectivos, aunque cumplan todos los requisitos legales para que se tornen eficaces, como es el caso de Brasil.

\section{LA DOGMÁTICA UNITÁRIA DE LOS DERECHOS HUMANOS Y LA TEORÍA DE LA RESERVA DE LO POSIBLE}

La polémica en torno al reconocimiento de la fundamentalidad de los derechos humanos sociolaborales sigue siendo muy actual. Eso porque, aunque consagrados expresamente en el texto constitucional de la mayoría de los Estados democráticos de derecho, incluyéndose Brasil, siempre son suscitadas controversias de cuño teórico en relación al estatus fáctico que esos derechos deben ocupar en el ordenamiento jurídico frente a los derechos de libertad, dado su inherente carácter prestacional.

Hay que notar que desde la promulgación de la Constitución brasileña, el 5 de octubre de 1988, los derechos sociales, en general, tienen ocupado un protagonismo sin precedentes entre los juristas, pasando a ser objeto de una crítica feroz justificada en la “exagerada” constitucionalización de esos derechos, llegándose a sugerirse, inclusive, una reforma constituyente en el sentido de excluir una serie de esos derechos fundamentales consagrados, especialmente, en su artículo $6^{\circ}$, como es el caso del derecho laboral.

Ahora bien, parece bastante obvia la constatación de que el reconocimiento constitucional expreso de esos derechos no implica en que estén siendo efectivamente cumplidos. En otras palabras, el hecho de que el legislador constituyente haya sido extremamente generoso al reconocer un rol significativo de derechos sociales no se refleja en su efectiva realización, lo que, por una parte, causa gran frustración social y, por otra, un esfuerzo hercúleo en deslegitimar jurídicamente esos derechos para justificar su incumplimiento.

En este sentido, vale recordar la advertencia de Streck (2004, p. 57) cuando señaló que el adviento de la actual Constitución no significó una satisfacción de todas las promesas de la modernidad. De ahí que la problemática en torno a esa cuestión se plasma una vez más en el ya referido dualismo lógico del "ser” y del “deber ser” que se ve reflejado en términos prácticos el descompás existente entre la eficacia de esos derechos y su efectividad, principalmente por tratarse de derechos que demandan acciones prestacionales, es decir, que exigen la utilización de recursos financieros del Estado para su implementación.

Tal vez por esa disconformidad es que la controversia existente en la esfera doctrinal y 
jurisprudencial sobre la fundamentalidad y legitimación de los derechos sociales, bien como acerca de su contenido y régimen jurídico, se haya reavivado, pareciéndonos necesario tratar de la cuestión, pero no solamente para subrayar su relevancia, sino que, igualmente, para posicionarnos en pro de la fundamentalidad de todos esos derechos.

En cuanto a la justificación de la fundamentalidad de los derechos sociales, hay que hacer destacar en la doctrina jurídica el célebre discurso de la paridad material entre todos los derechos fundamentales, por tratarse de derechos que forman un todo indivisible. En este sentido, hay que destacar la defensa de la indivisibilidad entre derechos de libertad y derechos sociales hecha por Novais (2003, 2009), para comprobar la viabilidad de una dogmática unitaria de derechos fundamentales.

Como observa el autor, en el plano jurídico, dos posiciones extremas pueden ser vislumbradas en lo que atañe a la discusión acerca de los derechos sociales. El primer posicionamiento, considerado más tradicional y preponderante en la doctrina, busca fundamentar la naturaleza de los derechos sociales contraponiéndolos a los derechos de libertad. Bajo esa perspectiva, se originarían dos grandes grupos de derechos fundamentales con características diferentes y regímenes jurídicos constitucionales distintos.

Una segunda postura, minoritaria, busca disolver la noción de derechos sociales en un proceso de atenuación de las disimilitudes entre los dos grupos de derechos fundamentales, a punto de concluirse por la existencia de un único tipo de derechos y de un régimen constitucional unitario que disponga sobre ellos.

La doctrina constitucional, al simplificar la distinción entre derechos sociales y derechos de libertad, asociando a estas categorías, respectivamente, una naturaleza positiva (de la cual resulta, generalmente, una obligación de hacer del Estado ) y una naturaleza negativa (en razón de la cual debe el Estado abstenerse de determinadas conductas), acabó por ensombrecer la multifuncionalidad de los derechos fundamentales, pues que, en verdad, tantos los dichos derechos de libertad, como los derechos sociales, poseen, indistintamente, las dos dimensiones.

De acuerdo con Shue (1980, p. 84), clasificar cada derecho como negativo o positivo es artificial, simplista y, además, un árido ejercicio. En este mismo sentido, señala Sepúlveda (2003, p. 123) que:

[...] a positive/negative distinction between the two sorts of rights cannot be made, and, as a result, the alleged difference in nature between them needs to be reappraised [...] The academic literature as well as the jurisprudence of the major of human rights supervisory bodies shows that positive and negative duties are part of the normative requirement of both sort of rights. 
De acuerdo con Novais, es cierto que una diferenciación estanque, firmada en la contraposición derechos de libertad versus derechos sociales, en la línea de la primera vertiente, apunta, desde luego, sus deficiencias, al paso que el acogimiento de la segunda corriente también merece reservas, pues no se puede ignorar la existencia de distinciones entre los dos derechos fundamentales, aunque estas estén firmadas bajo otros presupuestos.

Acerca de esas distinciones, el autor recuerda que se hace necesario, primeramente, tenerse en cuenta una clara separación entre las dimensiones objetiva y subjetiva de la norma de derechos fundamental, de las cuales suceden, respectivamente, un conjunto de deberes al Estado y pretensiones subjetivas de obtener la realización. de aquellos. En segundo lugar, la cualificación de un derecho como social es el resultado de la elevación de la dimensión principal del derecho social considerado como un todo, lo que, por obvio, no se agota en la totalidad de deberes y posiciones derivadas de cada uno de los derechos que los compone.

La tercera puntuación es la de que los derechos sociales son direccionados exclusivamente al Estado, lo que, consecuentemente, genera, para este último, un deber de protección de los particulares en sus relaciones privadas (NOVAIS, 2006, 2008). La cuarta ponderación del autor es la de que los derechos sociales son así definidos en razón de los deberes prestacionales fácticos que se imponen al Estado. Así, es menos la naturaleza del bien protegido por la norma que el tipo de deber que por ella es fundamentado que hace merecer la calificación de un derecho como social.

En quinto lugar, el constitucionalista portugués señala que, además de las prestaciones fácticas, los derechos sociales reclaman, igualmente, prestaciones normativas. Eso porque, en general, el Estado es llamado, primeramente, a determinar vía legislación las condiciones de realización de las prestaciones fácticas originadas de las normas de derechos sociales, por lo que estas pasan a depender, en regla, de aquellas.

En este contexto, las normas laborales serían un gran ejemplo de prestaciones normativas, pues su edición debe tener siempre como finalidad última la corrección de la desigualdad material existente entre los trabajadores y los empleadores existente en el campo económico, proporcionando al trabajador, en el ámbito jurisdiccional, una igualdad formal para poder enfrentar jurídicamente a su empleador.

Ahora bien, en sexto lugar, y por fin, argumenta que no se debe perder de vista que los derechos sociales poseen tanto una dimensión positiva, de la cual derivan los derechos a los cuales el Estado crie o fornezca prestaciones, cuanto una dimensión negativa, en razón de la cual el Estado debe no atentar, no afectar o no suprimir prestaciones ya conocidas o que el particular ya tiene acceso.

Según Novais, las objeciones al reconocimiento de la fundamentalidad de los derechos 
sociales estarían entonces relacionadas a tres factores: a) la dependencia expresiva de una reserva de lo posible (la cual generalmente es entendida como una reserva financiera); b) su estructura de derechos positivos (prestacionales, por tanto); y c) la indeterminabilidad de su contenido constitucional.

En función de esas particularidades, el autor advierte que, en el caso del no reconocimiento de la indivisibilidad de los derechos fundamentales, los derechos sociales no podrían jamás ser universalizados; no se constituirían como derechos subjetivos, por la ausencia de un contenido determinado; no estarían blindados de violaciones, pues que ni mismo estas serían identificadas; y, por fin, siquiera vincularían los poderes públicos, a no ser que, cuando mucho, de modo bastante mitigado.

Un punto neurálgico de la cuestión concierne a la caracterización de los derechos sociales como derechos a prestaciones fácticas. Pues bien, no hay como definirlos de otra manera, y tampoco negar que su realización es, en regla, onerosa a los cofres públicos. Luego, negarlo sería como negar la propia naturaleza de esos derechos.

Eso porque es un hecho que el Estado, por su vez, en un cuadro de escasez moderada, se ve obligado a hacer escojas y opciones políticas acerca de la ubicación de los recursos disponibles, decidiendo prioridades en cuanto a la realización de deberes. Pero eso lo les quita a los derechos sociales su dimensión de derechos humanos fundamentales, como llegan a defender algunos que cuestionan esa su esencia, lo que nos parece absurdo ${ }^{1}$.

Un otro argumento que suele ser utilizado en pro de la justificación de la unidad de los derechos fundamentales es lo que los derechos de libertad también están condicionados económica e financieramente. A bien decir, la reserva de lo posible no sería una particularidad de los derechos sociales, sino que, en última análisis, todos los derechos fundamentales exigen costes para el mantenimiento de su estructura de protección, pues se encuentran vinculados al propio funcionamiento del Estado de Derecho.

En este contexto, hay que recordar que la teoría de la reserva de lo posible es una construcción jurisprudencial del Tribunal Constitucional Federal alemán que fue utilizada por primera vez, en 1972, en la decisión denominada numerus clausus, que trataba sobre el derecho a las vacantes en universidades públicas, siendo que la Corte alemana entendió que los derechos fundamentales a las prestaciones positivas que resultan directamente de la Constitución deberían limitarse a los casos en que el individuo pueda racionalmente exigirlos de la sociedad.

El argumento principal fue que el legislador, al ejercer sus atribuciones, también debe

\footnotetext{
${ }^{1}$ Véase, entre otros: ATRIA (2005, p. 9-46).
} 
observar otros intereses de la comunidad, preservando. De acuerdo con la tesis del Tribunal, sería imprescindible preservar el equilibrio económico global, es decir, no se deberían instituir gastos y gravar exageradamente a la sociedad. Además, sería "una incomprensión del significado de libertad, si se diera una continua primacía de la libertad personal en detrimento de la capacidad funcional y del equilibrio de la sociedad como un todo” (CAPITANT, 2001, p. 308).

Sentado eso, las aportaciones de Holmes y Sunstein (2011, p. 38-40, 65) son de referencia obligatoria en el análisis del tema. Para los autores, los derechos y las libertades individuales también dependen fundamentalmente de una acción estatal vigorosa, y, por lo tanto, cuestan dinero al Estado. Eso porque "un derecho legal sólo existe sí y cuando tiene costos presupuestarios”, así que, tanto la calidad, como la extensión de la protección de los derechos, dependen de gastos privados y públicos, no siendo distinto con los derechos individuales que se financian con impuestos y no con tasas.

Además de los costos presupuestarios los derechos tienen costos sociales. De ahí que derechos como la educación o la protección de la propiedad privada, en la medida que invertir en su tutela, contribuye a aumentar extender o ampliar la base imponible - de la cual depende la protección activa de los derechos - hacia otras áreas. Tampoco se puede dejar de considerar en el costo de los derechos sus costos indirectos o gastos compensatorios. En definitiva: "Todos los derechos son costosos porque todos presuponen una maquinación eficaz de supervisión, pagada por los contribuyentes, para monitorear y controlar”.

Para Novais, sin embargo, esta idea solo puede ser considerada con alguna reserva. Eso porque la noción de derechos fundamentales como un todo impone la clara distinción, tanto en el ámbito de los derechos de libertad, como en el ámbito de los derechos sociales, entre deberes de respeto, protección y promoción.

En principio, la primera dimensión no importa en costes al Estado, pues que este, en razón de ella, debe solamente no intervenir en el acceso individual a bienes jurídicos fundamentales protegidos. Por su vez, delante de las dos últimas - y, sobretodo, de la última - el Estado tiene su actuación limitada por la disponibilidad de servicios e instituciones que le son impuestas. De ahí que, solamente considerando las dimensiones principales de los derechos fundamentales es que se puede establecer alguna diferencia en cuanto a la afectación de la llamada reserva de lo posible. Mientras que en derechos de libertad haya la predominancia del deber de respeto, los derechos sociales se relacionan, en regla, al deber de promoción.

Además, según el jurista portugués, hay también que diferenciarse la forma de afectación de la reserva en las dos categorías de derechos fundamentales. Mientras los costes importen el comprometimiento de la efectividad social de los derechos de libertad, en el caso de los derechos 
sociales, la reserva invade el plan jurídico-normativo y condiciona intrínsecamente la propia existencia del derecho.

Otro argumento de aproximación entre los derechos de libertad y los derechos sociales - y, consecuentemente, de defensa de la fundamentalidad de estos - es aquél de que ambas las categorías son afectadas por algún tipo de reserva que las acondiciona. De ahí que, mientras los derechos de libertad sufrirían los impactos de una “reserva general inmanente de ponderación”, los derechos sociales, además de esta restricción, estarían aún igualmente limitados por la reserva de lo posible.

La tesis de la "reserva general inmanente de ponderación” constituye la base de todos los análisis del autor y se resumiría como el presupuesto que justifica la ocurrencia de restricciones a los derechos fundamentales, por parte de los poderes públicos - y, particularmente, del legislador democrático - aunque no expresamente autorizadas por el texto constitucional. En este plan, la adopción de la reserva se relaciona, sobre todo, con la preocupación relativa al control de la constitucional de las interferencias en el ámbito de protección de los derechos fundamentales, lo que lo hace considerar la ponderación el test decisivo en un Estado de Derecho (NOVAIS, 2003, p. 569635).

A pesar de eso, asegura el jurista que hay una distinción substancial entre la competencia del poder judicial para decidir a respeto de derechos a depender del tipo de reserva del posible que los afecte. Así, mientras el control de las restricciones a derechos condicionados solo por la reserva de la ponderación es pleno, el control cuando a esta se suma la reserva de lo posible se torna reducido.

En este sentido, por tratarse de derechos que involucran prestaciones fácticas, no cabría al juez, ab initio, definir prioridades en cuanto a la distribución de recursos, por tratarse de competencia del Legislativo, sin embargo, es completamente plausible y debido que realice en control en el sentido de evaluar si la alegada falta de recursos es suficiente para, en el caso concreto, alejar una pretensión individual. No obstante, hay que traer a colación las oportunas consideraciones de Dallari (1996, p. 87) para una reflexión más profundizada del tema:

O juiz recebe do povo, através da Constituição, a legitimação formal de suas decisões, que muitas vezes afetam de modo extremamente grave a liberdade, a situação familiar, o patrimônio, a convivência na sociedade e toda uma gama de interesses fundamentais de uma ou de muitas pessoas. Essa legitimação deve ser permanentemente complementada pelo povo, o que só ocorre quando, segundo a convicção predominante, os juízes estão cumprindo o seu papel constitucional, protegendo eficazmente os direitos e decidindo com justiça. Essa legitimação tem especial importância pelos efeitos políticos e sociais que podem ter as decisões judiciais.

En este orden de ideas, parece ser que la cuestión no es tanto definir si el Poder Judicial tiene o no competencia para emitir juicios cuando está en causa elecciones de prioridades presupuestarias, pero sí, si tal juicio es emitido en los límites impuestos por el principio de la separación de los poderes. 
De esta manera, concluye Novais que la diferencia en lo que concierne a la amplitud del control consiste en la distinción verdaderamente relevante entre los derechos fundamentales, considerados en su dimensión principal, pero que de ningún modo pone en causa la fundamentalidad de los derechos sociales.

La segunda objeción al reconocimiento de la fundamentalidad de los derechos sociales suele estar asociada a la relación estricta entre derechos de libertad y dimensión negativa versus derechos sociales y dimensión positiva. La noción de derecho fundamental como un todo fragiliza esa conexión, una vez que identifica ambas las dimensiones tanto los derechos de libertad como los derechos sociales.

Cabría solamente ponderar que, únicamente frente a su dimensión principal es que los derechos sociales pueden ser considerados derechos positivos sujetos a una justicialidad enflaquecida. Además, teniendo los derechos de libertad igualmente una dimensión positiva, en lo que respeta a esta poseen justicialidad menos densa, al mismo paso que, en relación a la dimensión negativa, derechos de libertad y derechos sociales son igualmente justiciables. La fundamentalidad de los derechos sociales tampoco se ve aquí comprometida.

Por ende, la tercera objeción a la fundamentalidad de los derechos sociales se ampara en el argumento de que es una particularidad de estos derechos la indeterminación de su contenido patrimonial, lo que, en tesis, no se verificaría, por ejemplo, en los derechos de libertad.

De acuerdo con ese argumento, por tratarse de derechos profundamente condicionados por el montante presupuestario de lo cual dispone el Estado, y en la hipótesis de eventuales mutabilidades del escenario económico afectar su propia exigibilidad, entonces sería más recomendable que la densificación del contenido de los derechos sociales ocurriera solamente en el ámbito infraconstitucional. La consecuencia de la adopción de este razonamiento afectaría la propia fundamentalidad de los derechos sociales.

Hay que considerarse que no es menos verdad que los de derechos de libertad también sufren una indeterminación similar a los derechos sociales en el plano constitucional. Para Novais (2003, p. 427), el contenido protegido por la norma de derecho fundamental presente en el texto constitucional está solamente prima facie definido, debiéndose considerar llevar en cuenta el resultado de la aplicación de mecanismos de interpretación de las normas, pero cabe, en la mayoría de los casos, al legislador ordinario algún tipo de conformación, afectación, disposición, restricción desde las cuales se llega al contenido de los derechos sociales en especie.

La indefinición del contenido de los derechos sociales, visto como el problema más grave por la doctrina (en razón de que serían derechos típicamente prestacionales, condicionados a la 
reserva de los posible y que, en principio, esa indefinición no atinge los derechos de libertad - por lo menos en su dimensión principal) es plenamente superable a lo largo del tiempo, en la medida en que la actuación legislativa precisa el contenido de los derechos sociales, restando, por razones de igualdad y confianza, el Estado a ellos vinculado.

En definitiva, las diferencias estructurales de las normas de derechos de libertad y derechos sociales no justificarían un tratamiento distinto entre los bienes por ellas tutelados, existiendo simplemente una diferenciación sistemática, formal y orgánica entre los dos tipos de derechos (2010, p. 349), pues todos los bienes jurídicos protegidos poseen el mismo relievo constitucional, cual sea: asignar a las personas la garantía de su reconocimiento frente a los poderes públicos y a terceros, como reflejo de la expresión jurídica basilar del cualquier Estado democrático de derecho que es el principio de la dignidad de la persona humana.

\section{HACIA LA EXIGIBILIDAD DE LOS DERECHOS HUMANOS SOCIOLABORALES EN EL ORDEN JURÍDICO BRASILEÑO}

A pesar de la existencia de toda una fundamentación jurídica internacional que, por si sola, justificaría la exigibilidad jurídica de los derechos sociales, muy especialmente de los laborales, no es raro, como señalan Abramovich y Courtis (2002, p. 19), encontrar opiniones que, negando todo valor jurídico a esos derechos, los caracterizan como “meras declaraciones de buenas intenciones, de compromiso político y, en el peor de los casos, de engaño o fraude tranquilizador”.

Tal posicionamiento parece sinsentido cuando se piensa que un Estado democrático de derecho se consolida justamente con la efectiva defensa de los derechos sociales, ofreciendo a sus ciudadanos condiciones de paridad para el pleno ejercicio de los derechos humanos en sociedad, inclusive las libertades públicas, como previamente se ha señalado. Al respecto, observa Sanchís (2004, p. 145-146) que:

[...] existe una cierta conciencia de que los derechos sociales en general y, muy particularmente, los derechos prestacionales o no son auténticos derechos fundamentales, lo que representa una suerte de retórica jurídica, o bien, en el mejor de los casos, son derechos disminuidos o en formación. Esto ocurre incluso en la que parece ser la filosofía política dominante, que concibe estos derechos como expresión de principios de justicia secundarios, cuando no peligrosas confirmaciones del criterio utilitarista que amenaza el disfrute de los derechos individuales.

Además, ese tipo de interpretación resulta bastante peligrosa, a la vez que, al aproximar los derechos sociales a meros “mandatos de carácter programático”, restarán vaciados de su carácter vinculante y, por consiguiente, de su propia exigibilidad. En otras palabras, a recomendaciones o programas que se irán cumpliendo de acuerdo con el monto de recursos económicos de que dispongan

Revista da Faculdade de Direito - UFPR, Curitiba, vol. 61, n. 3, set./dez. 2016, p. 11 - 38 
los Estados y conforme a su propia capacidad administrativa y judicial para desarrollar los servicios públicos a través de los cuales esos derechos sociales deben ser alcanzados.

Es importante subrayar en ese contexto que lo único que exige la normativa internacional sobre trabajo es precisamente que los Estados promuevan una legislación de mínimos, es decir, que cada uno reconozca un núcleo de derechos humanos irreducibles en pro de sus ciudadanos, no habiendo distinción, $a b$ initio, si la protección ofrecida se da a nivel constitucional o infraconstitucional - aunque parezca más razonable que los derechos fundamentales deberían siempre estar constitucionalmente garantizados.

Consecuentemente, la constitucionalización de los derechos sociales o la incorporación de la normativa internacional acerca de ellos no será necesaria cuando los niveles de protección social ofrecidos por la vía legislativa infraconstitucional y por las políticas públicas, sean suficientes, o incluso superiores, para garantizarlos, desmereciéndose la alternativa de constitucionalización, sea a través del Poder Constituyente o por medio del reconocimiento de tratados y convenciones internacionales. Pero, infelizmente, la regla no es esa.

En el ámbito específico de análisis del derecho constitucional brasileño, no hay que hacerse cualquier restricción a la aplicabilidad plena de la teoría de la dogmática unitaria de la derechos fundamentales, sino todo lo contrario. Como reflexiona Sarlet (2001, p. 11), el solo hecho de que los derechos fundamentales estén formalmente reconocidos en la Constitución ya implicaría en una presunción en favor de la fundamentalidad también material de esos derechos y garantías, además de su reconocimiento formal:

Na Constituição de 1988, esta fundamentalidade formal recebeu especial dignidade, revelando-se não apenas na hierarquia normativa superior das normas constitucionais em geral, mas principalmente no fato de que, de acordo com o disposto no art. $5^{\circ}, \S 1^{\circ}$ da nossa Carta Magna, "as normas definidoras dos direitos e garantias fundamentais têm aplicação imediata”. Além disso, encontram-se os direitos fundamentais protegidos não apenas contra o legislador ordinário, mas até mesmo contra a ação do poder constituinte reformador, já que integram - ao menos de acordo com o nosso entendimento - o rol das "cláusulas pétreas" do art.60, § $4^{\circ}$, inc. IV, da CF.

En la esfera del sistema constitucional brasileño, parece no restar duda de que todos los derechos explícitamente reconocidos en la Carta Magna son derechos fundamentales, y más, el hecho de que algunos derechos sociales no estén ubicados en el Titulo II, sino que, en otras partes, no les quita de forma alguna esa naturaleza. Además, es imperioso traer la expresa disposición prevista en el párrafo segundo del artículo $5^{\circ}$ de que los derechos y garantías dispuestos en los tratados internacionales regularmente firmados e incorporados por Brasil serán considerados igualmente como derechos fundamentales. Por lo tanto, parece que la fundamentalidad de los derechos sociales se ve plenamente justificada. 
En este contexto, merece la pena destacar la diferenciación propuesta por Young (2012, p. 6), entre constitucionalizar y constituir derechos:

To constitute rights, in the special meaning given to that term [...] is to make them effective within a legal system. To constitute is not to constitutionalize, although the two processes are related, and assist each other. To constitutionalize commonly refers to the act of entrenching a commitment in constitutional text - the capitalized, written, Constitution: committing to text what no constitutional government can oust. To constitutionalize is often to leave abstract, to maximize present-day consensus and minimize the disruption of future contingencies. [...] To constitute, on the other hand, is to socially institute, so that the commitments are committed to social understanding, and are realized effectively in law.

El argumento principal de los Estados para la inobservancia de los derechos sociales es lo de la ya referenciada "reserva de lo posible”, idea asociada a la negación teórica de una dogmática unitaria de los derechos humanos que clasifica los derechos sociales como derechos prestacionales dependientes de la existencia de una disponibilidad económica del Estado para que sean cumplidos, como analizado anteriormente.

Al tratar específicamente del derecho social a la salud, Hernández (2010, p. 24) destaca que para que este derecho sea atendido, se depende de recursos económicos disponibles y que, solamente dentro de lo posible, puede ser judicialmente invocado directamente desde la Constitución. Otro punto de relieve es señalado por Abramovich y Courtis (2009, p. 16): la falta de especificación concreta del contenido de los derechos sociales genera un obstáculo a su propia justiciabilidad, pues cuando una Constitución o un tratado internacional de derechos humanos tratan de derechos sociales, resulta difícil saber cuál es la medida exacta de las prestaciones o abstenciones debidas.

Hay que subrayar, desde luego, que el posicionamiento adoptado por algunos Estados choca claramente con la Observación núm. 3 del Comité de Derechos Económicos, Sociales y Culturales de la ONU (CESCR), poniendo de relieve que, aunque se demuestre que los recursos disponibles sean insuficientes, sigue en pie la obligación de los Estados Partes de asegurar el disfrute más amplio posible de los derechos previstos en el PIDESC, dadas las circunstancias reinantes.

En definitiva, el Comité ha señalado que no se eliminan de ninguna manera las obligaciones de vigilar la medida de la realización o, más especialmente, de la no realización, de los derechos económicos, sociales y culturales y de elaborar estrategias y programas para su promoción, como resultado de las limitaciones de recursos (ONU, 1990).

Igualmente, el argumento de la reserva de lo posible aplicable a la realización de los derechos sociales parece bastante peligroso, de ahí que la doctrina, y también los tribunales, pasaron a restringir su aplicabilidad. Como observa Silva (2008, p. 574-575), los derechos fundamentales tienen un ámbito de protección amplio, a pesar de estar sujetos a restricciones proporcionales y constitucionalmente justificables, como, en verdad, todos los derechos fundamentales están, pues no 
existen derechos fundamentales absolutos.

Partiéndose del razonamiento de que los derechos sociales presentan un amplio contenido que los caracterizan, su restricción quedaría limitada a un núcleo esencial que, asociado al principio de la dignidad de la persona humana, dio a luz a la teoría del "mínimo existencial" (Existenzminimum). Por lo tanto, la teoría de la reserva de lo posible debería llevar en consideración ese mínimo existencial de derechos sociales fundamentales, denominados “originarios” (Originären Leistungsansprüche), como un límite razonable a su aplicación.

El contenido de ese concepto de “mínimo social”, como analiza Queiroz (2006, p. 150), debe ser principalmente positivo, no debe ser interpretado de manera restrictiva, sino que, debe desarrollarse en una perspectiva abierta y casuística, pues es un concepto de evaluación; un valor constitucional que se presenta como el fundamento y base del orden legal y constitucional. Sin embargo, como advierte la jurista portuguesa, el problema que se vislumbra es lo de redefinir los derechos para establecer una nueva síntesis de lo que abarcaría el concepto de "mínimo existencial”.

Conforme Alexy (2008, p. 508), las “restricciones que respeten la máxima de la proporcionalidad no violan la garantía del contenido esencial, aun cuando haya, en el caso concreto, no reste nada del derecho fundamental” y, en lo que se refiere al mínimo existencial en derechos sociales, "el sopesamiento puede conducir, en circunstancias distintas, a distintos derechos definitivos”. En cualquier caso, solo se admitirían límites o restricciones a los derechos sociales que estuvieran fuera del ámbito de protección de ese mínimo innegociable.

Ahora bien, ¿a quién cabrá la delimitación de ese mínimo? ¿a los Estados individualmente? Si la respuesta es afirmativa: ¿cabrá al Poder Legislativo determinar el mínimo existencial, o al Poder Judicial hacerlo mientras los casos concretos vayan surgiendo?; ¿ o correspondería a la sociedad internacional en conjunto definirlo? En este caso, ¿lo haría por medio de los organismos internacionales de protección a los derechos humanos o a través de las decisiones de las cortes internacionales de justicia?

No es nada fácil la tarea de configuración de lo que sería lo mínimo existencial frente a la diversidad económica, política y social que caracteriza la sociedad internacional. Además, los Estados siempre pueden hacer uso del argumento de la soberanía para justificar un mínimo existencial por debajo de lo establecido por el Derecho Internacional, principalmente en un momento como el actual, cuando los están buscando cada vez más justificativas políticas y económicas para el incumplimiento de derechos humanos.

Estapà (2013, p. 56) subraya que, muchas veces, gran parte de los problemas que tratan de derechos sociolaborales se pueden resolver por vía legislativa, sin ningún desembolso por parte del 
Estado (por ejemplo: igual salario por igual trabajo; prohibición del trabajo infantil; seguridad e higiene en el trabajo, etc.), mostrándose las prestaciones normativas muy eficientes para la corrección de las desigualdades materiales en el ámbito de los derechos sociolaborales. Por otro lado, hay que señalar que la normalización nunca fue sinónimo de efectividad real.

En lo que atañe a la exigibilidad jurídica de esos derechos, en la órbita de la acción normativa de la OIT parece no existir dudas de que se tratan de derechos humanos vitales que atienden los objetivos y fines de la OIT y que, por ello, estarían dotados de esa exigibilidad jurídica, independiente, incluso, de su reconocimiento por los Estados que no sean parte, pues son considerados como “mínimos”, ya que están intrínsecamente vinculados con la dignidad de la persona humana, lo que los torna universales.

Hay que destacar que la universalidad debe atender a objetivos de política social que sean realistas y útiles, independientemente del grado de desarrollo que hayan alcanzado los Estados parte, es decir, se debe llevar en consideración las disparidades políticas, sociales y culturales que componen y caracterizan la sociedad internacional, como señala la propia OIT en el artículo 19, 3 de su Constitución, al afirmar que cuando ésta elabore un convenio o recomendación de carácter general, deberá "tener en cuenta aquellos países donde el clima, el desarrollo incompleto de la organización industrial u otras circunstancias particulares hagan esencialmente diferentes las condiciones de trabajo” y deberá proponer "las modificaciones que considere necesarias de acuerdo con las condiciones peculiares de dichos países”.

Infelizmente, esa reserva puede crear - como de hecho suele ocurrir - una excusa legitima a la puesta en práctica de los derechos laborales por los Estados, de ahí la necesidad de considerar lo mínimo existencial. Es por eso que Ackerman (1994, p. 3) defiende que la exigibilidad jurídica debe ser planteada en términos absolutos sin que la "falta de ratificación expresa de los Convenios OIT pueda ser excusa para la violación de los derechos humanos fundamentales.

El otro punto señalado en relación a la exigibilidad de esos derechos es lo de tornarlos realmente justiciables. Como reflexionan señalan Abramovich y Courtis (2002, p. 23) acerca del tema, la magistratura suele emplear un criterio sumamente restrictivo a la hora de evaluar su facultad de invalidar decisiones que pueden calificarse como políticas. En sus palabras:

[...] cuando la reparación de una violación de derechos sociales importa una acción positiva del Estado que pone en juego re- cursos presupuestarios, afecta de alguna manera el diseño o la ejecución de políticas públicas, o implica tomar una decisión acerca de qué grupos o sectores sociales serán prioritariamente auxiliados o tutelados por el Estado, los jueces suelen considerar que tales cuestiones son propias de la competencia de los órganos políticos.

Aun dentro de ese contexto, hay que llamar la atención sobre la inadecuación de la normativa 
procesal para la tutela de los derechos sociales. Como es sabido, las normas procesales regulan la función jurisdiccional del Estado en todos sus aspectos y fijan el procedimiento que se ha de seguir para obtener la actuación del derecho positivo en los casos concretos, determinando las personas que deben estar sometidas a dicha jurisdicción y los funcionarios encargados de ejercerla (ECHANDÍA, 1984, p. 6). En otras palabras, la norma procesal tiene como objetivo y fin la realización del derecho objetivo través de la tutela del derecho subjetivo, mediante el ejercicio de la función de jurisdicción (BAUTISTA,1984, p. 15).

No obstante, en general, las acciones judiciales tradicionales tipificadas por el ordenamiento jurídico han sido pensadas para la protección de los derechos civiles clásicos. Así que, la efectividad de los derechos sociolaborales solo será alcanzada si, además de la norma constitucional del Estado que prevea la exigibilidad inmediata de referidos derechos, también exista una preocupación en tornarlos justiciables por medio de reglamentación, abriéndose vías procesales idóneas para su alcance.

Al final, no basta que el ciudadano posea derechos cristalizados en una constitución si su efectividad no se hace posible. Tal vez sería demasiado maquiavélico afirmar que el Poder Legislativo, al elaborar la norma procesual que prevé la forma de instrumentalización de la tutela de derechos humanas, pensara adrede en tornarla de difícil realización. Por otra parte, mucho más factible parece la consideración de que el Poder Judicial - en especial de los tribunales constitucionales de los Estados -, imponen trabas a su efectivo cumplimiento.

Abramovich y Courtis (2002, p. 25-26) señalan algunos ejemplos para demostrar las dificultades que genera el marco teórico en el que se fundan las acciones tradicionales para proteger adecuadamente derechos sociales:

a) La incidencia colectiva de la mayoría de los derechos sociales provoca problemas de
legitimación activa, que no se limitan a la etapa de formulación de la acción, sino que se
prolongan durante las diferentes etapas del proceso, ante la inexistencia de mecanismos de
participación adecuada de los sujetos colectivos o de grupos numerosos de víctimas en las
diferentes diligencias e instancias procesales. Esta circunstancia pone en evidencia que las
acciones y los procedimientos están previstos para dilucidar conflictos individuales; b) Las
violaciones de los derechos sociales requieren al mismo tiempo satisfacción urgente y
amplitud de prueba, pero estas dos cuestiones son excluyentes para la elección de los
mecanismos tradicionales de tutela. Acciones tales como la de amparo, tutela, protección u
otras similares requieren un derecho líquido, y las medidas cautelares un derecho verosímil,
y en ambos tipos de procedimiento el ordenamiento procesal y la jurisprudencia restringen al
mínimo el marco probatorio del proceso; c) Las sentencias que condenan al Estado a cumplir
obligaciones de hacer no cuentan con resguardos procesales suficientes y resultan por ello de
dificultosa ejecución.

Ahora bien, desde la perspectiva internacional, el problema parece resumirse a la falta de un tribunal supralegal que los torne exigibles, hecho que es más bien la regla general. Sin embargo, como 
advierte Estapà (2013, p. 59), la carencia de mecanismos jurisdiccionales, al menos en el plano universal, no es óbice para considerar el respeto a los derechos económicos, sociales y culturales tan exigible como lo puedan ser otras categorías de derechos; o, en general, cualquier obligación jurídica internacional.

En definitiva, como ya señaló, hace tiempo, Canotilho (1988, p. 21), lo que se espera, por lo tanto, partiéndose de las normas internacionales de protección de los derechos humanos considerados universales, indivisibles, interdependientes e interrelacionados - es que "tomemos a sério os direitos económicos, sociais e culturais”, porque, en este contexto, “o fazer algo a alguém não é simplesmente um imperativo moral; é juridicamente um direito com a conseqüente obrigatoriedade da sua realização”.

\section{CONSIDERACIONES FINALES}

Como se ha analizado, la dignidad es un valor inherente a la persona como ser individual y social, con sus características y condiciones particulares, por el solo hecho de ser persona. Por consiguiente, la dignidad es el punto común de unión y existencia entre todos los seres humanos, justificando la garantía de cumplimiento de determinados derechos humanos que objetivan protegerla. En este contexto, se insieren los derechos sociolaborales, pues su propósito es únicamente asegurar un mínimo de condiciones para el reconocimiento y la protección a nivel universal de la dignidad en el ámbito del trabajo.

Si por un lado es verdad que al Estado cabe asegurar esos derechos mínimos necesarios conducentes al reconocimiento de la dignidad a sus ciudadanos, especialmente en la esfera laboral, por otro, hay que subrayarse que el Estado es solamente un cuerpo artificial que traduce los anhelos de un gobierno formado por hombres - y que ni siempre está volcado a la búsqueda de la satisfacción del fin social, dejando de distinguir, incluso, lo público de lo privado. Por esa razón, se considera imperioso el reconocimiento de la normativa internacional para garantizar la preservación de la dignidad por encima de los intereses del Estado soberano.

Los derechos sociolaborales forman parte indivisible de los derechos humanos fundamentales, siendo totalmente equiparables a los derechos civiles y políticos, razón por la cual deben ser tratados dentro de una misma dogmática jurídica. De ahí que asociarlos a categorías distintas, es decir, una negativa, y otra positiva, acaba por ensombrecer su multifuncionalidad, pues ambos poseen, indistintamente, las dos dimensiones y, por lo tanto, la misma naturaleza jurídica de derechos humanos. 
Para que se pueda cumplirlos es importante que haya especificación concreta de su contenido para no generar obstáculos a su justiciabilidad. La falta de esta precisión impide que se determine exactamente la medida de su incumplimiento. En este sentido, se constató que la teoría del mínimo existencial puede ser una manera eficaz para que el Poder Judicial establezca un límite razonable a su aplicación.

En este sentido, el papel de la OIT cobra relieve, pues es el único Organismo tripartito especializado de la ONU, cuyo objetivo es promover un reconocimiento por los Estados cada vez mayor de los derechos humanos sociolaborales considerados fundamentales, por medio de la elaboración de convenios y recomendaciones, pero también a través de acciones de cuño no normativo.

Sentado todo lo anterior, parece ser que el camino de la efectividad de los derechos sociolaborales sea realizable, en un primer momento, su reconocimiento en los ordenamientos internos de los Estados miembros de la OIT para que ganen el relieve y la exigibilidad jurídica compatibles con su importancia, alcanzando, así, la efectividad plena.

Entre los muchos obstáculos a la realización de los derechos humanos sociolaborales por los Estados, parece ser que el argumento de los altos costes, asociado muchas veces a la convicción de que esos derechos se reducen a un universo de mandatos de carácter programáticos, obstaculizan su puesta en marcha, desprestigiando, inclusive, todo su esfuerzo en el sentido de alcanzar sus propósitos fundacionales.

Como se ha estado señalando a lo largo de todo el artículo, los intereses políticos se revisten de la protección que la soberanía ofrece a los Estados en la sociedad internacional, legitimando indebidamente, por supuesto - la negativa del Estado para el cumplimiento de derechos fundamentales, lo que parece, mínimamente, un contrasentido, principalmente cuando esos derechos están plasmados en las cartas constitucionales de esos Estados como normas de aplicabilidad inmediata. Y en este catálogo de ideas, siempre vale recordar la ya referida dicotomía del "ser” y “del deber ser” que parece permear todo el universo jurídico, especialmente en lo que concierne a los derechos humanos.

Ahora bien, aunque haya otros medios de exigibilidad de los derechos sociales, la vía judicial es y continuará siendo el camino más adecuado, legítimo y eficiente de alcanzar la tutela de los derechos fundamentales en general, por representar uno de los poderes del Estado que, gozando de autonomía funcional, administrativa y presupuestaria, tiene garantizada su actuación independiente desde la perspectiva del sistema de contrapesos y equilibrios caracterizador del Estado democrático de derecho (al menos en teoría). 
En este sentido, la función del juez y, especialmente, de aquellos que componen las cortes constitucionales, es de superación del positivismo restrictivo que los circunscribe a un universo mecanizado de aplicación de ley, correspondiéndoles en la contemporaneidad interpretar y adecuar la ley consonante los principios jurídicos generales que, incluso, han servido de base para su elaboración.

En la esfera internacional, la exigibilidad jurídica de los derechos sociolaborales fundamentales, derivada de la Constitución de la OIT y de la Declaración de Filadelfia, se restringe solamente a los Estados miembros de la OIT, suscitándose entonces la cuestión de su universalidad y de su exigibilidad jurídica a los Estados que no sean miembros, recordándose aquí que, mismo a los Estados miembros, el argumento de los altos costes y de falta de estructura para su concreción acaba por impedir la exigibilidad plena de esos derechos.

Asimismo, no es demasiado recordar que los convenios sólo son exigibles si ratificados por los Estados miembros, por su naturaleza de tratados-leyes (o tratados-normativos), y la ratificación es un acto inherente al ejercicio de la soberanía pues, como se ha enfatizado, el consentimiento sigue siendo el corolario de la soberanía, aunque se traten de derechos humanos fundamentales.

Frente a todo lo expuesto, es posible afirmar que se está viviendo un retroceso en la trayectoria de la protección de los derechos humanos y consolidación de un sistema de cuño universal, tras años de lucha por el reconocimiento de un conjunto de derechos fundamentales que, aparentemente, parecían estar consolidados como clausula pétreas en la normativa internacional y en la mayoría de las constituciones de los Estados democráticos de derecho.

Lo peor es que todas esas restricciones a la aplicabilidad de los derechos humanos, especialmente los sociales, vienen legitimándose política y jurídicamente en el secular concepto de soberanía estatal. Como es bien sabido, el consentimiento continúa siendo el corolario de la soberanía y, como se ha afirmado anteriormente, la herencia del Realismo clásico aún es muy latente en la configuración de las relaciones internacionales.

Por esas y otras razones, infelizmente, la mayoría de los Estados viene imponiendo trabas para la aceptación, incorporación y, finalmente, aplicabilidad en su ordenamiento jurídico interno de las normas internacionales de derechos humanos. $\mathrm{Y}$ en este juego de intereses quien pierde es siempre el verdadero detentor de la soberanía: el pueblo.

Por lo que se refiere específicamente a Brasil, la Constitución brasileña es clara en lo que concierne a la aplicabilidad de la normativa internacional sobre derechos humanos en su ordenamiento jurídico, previendo en el párrafo $2^{\circ}$ del artículo $5^{\circ}$ que los tratados internacionales sobre derechos humanos tendrán el mismo valor constitucional reconocido a los derechos fundamentales 
en ella originalmente previstos y, por lo tanto, perfilando su exigibilidad jurídica.

Al hilo de todo lo expuesto, desde el punto de vista formal, no existen impedimentos a la aplicabilidad de la normativa internacional de derechos humanos en el ordenamiento jurídico interno, sino que todo lo contrario, teniéndose en cuenta lo expresamente previsto en el párrafo $1^{\circ}$ del artículo $5^{\circ}$, que deja claro que las normas que traten de derechos y garantías fundamentales deben tener aplicación inmediata. Sin embargo, se constata una reticencia por parte de los tribunales de aplicar la normativa internacional, pues los jueces optan, invariablemente, por juzgar y fundamentar sus sentencias de acuerdo con la legislación doméstica.

\section{REFERENCIAS}

ABRAMOVICH, Víctor; COURTIS, Christian. Apuntes sobre la exigibilidad judicial de los derechos sociales. In: COURTIS, Christian, SANTAMARÍA, Ramiro Ávila (Ed.). La protección judicial de los derechos sociales. Quito, Ecuador: Ministerio de Justicia y Derechos Humanos, 2009, p. 3-30.

Los derechos sociales como derechos exigibles. Madrid: Trotta, 2002.

ACKERMAN, Mario Eduardo. Volver a las fuentes y afirmarse en los principios. In: OIT. Pensamientos sobre el porvenir de la justicia social - Ensayos con motivo del 75 aniversario de la OIT. Ginebra: Oficina Internacional del Trabajo, 1994, p. 1-6.

ALEXY, Robert. Teoria dos direitos fundamentais. São Paulo: Malheiros, 2008.

ARENDT, Hannah. La condición Humana. Barcelona: Paidós, 1993.

ATRIA, Fernando. Existem direitos sociais? In: MELLO, Cláudio Ari (Coord.). Os desafios dos direitos sociais. Porto Alegre: Livraria do Advogado, 2005, p. 9-46.

BAUTISTA, José Becerra. Introducción al estudio del derecho procesal civil. Ciudad de México: Cardenas Editorial, 1984.

BOBBIO, Norberto. A era dos direitos. Rio de Janeiro: Campus, 1992.

CAPITANT, David. Les effets juridiques des droits fondamentaux en Allemagne. París: LGDJ, 2001.

CASSESSE, Antonio. Human rights in a changing world. Philadelphia: Temple University Press, 1990.

CANOTILHO, Joaquim José Gomes. Tomemos a sério os direitos económicos, sociais e culturais. In: Boletim da Faculdade de Direito da Universidade de Coimbra. Coimbra, núm. especial: Estudos em homenagem ao Prof. Dr. António Arruda Ferrer Correia, n. 3, 1988. p. 461-500.

DALLARI, Dalmo de Abreu. O poder dos juízes. São Paulo: Saraiva, 1996. 
DWORKIN, Ronald. El dominio de la vida. Barcelona: Ariel, 1998.

ECHANDÍA, Hernando Devis. Teoría general del proceso. Buenos Aires: Editorial Universidad, 1984, tomo I.

ESTAPÀ, Jaume Saura. La exigibilidad jurídica de los derechos humanos: especial referencia a los derechos económicos, sociales y culturales (DESC). In: PÉREZ, Jordi Bonet; ESTAPÀ, Jaume Saura (Ed.). El Derecho internacional de los derechos humanos en tiempos de crisis: estudios desde la perspectiva de su aplicabilidad. Madrid: Marcial Pons, 2013, p. 53-70.

FLORES, Joaquín Herrera. El vuelo de Anteo: derechos humanos y crítica de la razón liberal. Bilbao: Desclée de Brouwer, 2000.

GEREMEK, Bronislaw. La piedad y la horca: historia de la miseria y de la caridad en Europa. Madrid: Alianza Editorial, 1998.

HERNÁNDEZ, J. M. Casal. Los derechos fundamentales y sus restricciones. Caracas: Legis, 2010.

HOBSBAWM, Eric. A Era das revoluções: Europa 1789-1848. 19. ed. São Paulo: Paz e Terra, 2005.

HOLMES, Stephen; SUSTEIN, Cass R. ¿El costo de los derechos: por qué la libertad depende de los impuestos? Buenos Aires: Siglo 21 Editores, 2011.

KANT, Manuel. Fundamentación de la Metafísica de las Costumbres. San Juan, Puerto Rico: Pedro M. Rosario Barbosa, 2007.

LOPEZ, Diego. Derechos, Trabajo y Empleo. Santiago de Chile: LOM Ediciones, 2004.

LUÑO, Antonio Enrique Pérez. Derechos Humanos, Estado de Derecho y Constitución. 8. ed. Madrid: Tecnos, 2003.

MARTINS FILHO, Ives Gandra da Silva. Manual de Direito e Processo do Trabalho. 18. ed. São Paulo: Saraiva, 2009.

NOVAIS, Jorge Reis. Direitos sociais: teoria jurídica dos direitos sociais enquanto direitos fundamentais. Coimbra: Coimbra, 2009.

A intervenção do provedor de justiça nas relações entre privados. In: RODRIGUES, Henrique A. F. do N. O provedor de justiça: novos estudos. Lisboa: Provedoria de Justiça, 2008. p. 227-291.

. Direitos fundamentais: trunfos contra a maioria. Coimbra: Coimbra Editora, 2006.

As restrições a direitos fundamentais não expressamente autorizadas pela Constituição. Coimbra: Coimbra, 2003.

OIT. Constitución de la Organización Internacional del Trabajo y otros textos seleccionados. Ginebra: Oficina Internacional del Trabajo, 2010, 97p. [consulta: 19 de abril de 2015]. Disponible en: <https://goo.gl/dhbuiX>. 
ONU. Primer Informe de la Organización Internacional del Trabajo a las Naciones Unidas (1947): Apéndices, Vol. 2, 10p, p. 24. [consulta: 25 de noviembre de 2015]. Disponible en: $<$ https://goo.gl/dhbuiX $>$.

PÉREZ, Jordi Bonet. Mundialización y régimen jurídico internacional del trabajo: la Organización Internacional del Trabajo como referente político-jurídico universal. Barcelona: Atelier, 2007.

. Principios y derechos fundamentales en el trabajo: la Declaración de la OIT de 1998. Bilbao: Instituto de Derechos Humanos de la Universidad de Deusto, 1999. (Cuadernos Deusto de Derechos Humanos, núm. 5)

PÉREZ LUÑO, Antonio-Enrique. Los derechos sociales y su significación actual. In: ZAPATERO GÓMEZ, Virgilio; GARRIDO GÓMEZ, María Isabel (Ed.). Los derechos sociales como una exigencia de la justicia. Madrid: Universidad de Alcalá, 2009, p. 37-58.

PIOVESAN, Flávia. Temas de direitos humanos. 5. ed. São Paulo: Saraiva, 2012.

QUEIROZ, Cristina. Direitos fundamentais sociais: funções, âmbito, conteúdo, questões interpretativas e problemas de justiciabilidade. Coimbra: Coimbra Editora, 2006.

RIEZNIK, Pablo. Las formas del trabajo y la historia. 2. ed. Buenos Aires: Biblos, 2004.

SACHS, Ignacy. Desenvolvimento, Direitos Humanos e Cidadania. In: PINHEIRO, Paulo Sérgio; GUIMARÃES, Samuel Pinheiro (Org.). Direitos humanos no século XXI. Brasília: Instituto de Pesquisa de Relações Internacionais/Fundação Alexandre Gusmão, 1998, p. 155-166.

SANCHÍS, Luis Prieto. Los derechos sociales y el principio de igualdad sustancial. In: AÑON, María José (Ed.). La universalidad de los derechos sociales: el reto de la inmigración. Valencia: Tirant Lo Blanch, 2004, p. 111-170.

SARLET, Ingo Wolfgang. Os direitos sociais na Constituição de 1988. Revista Diálogo Jurídico, 2001, ano I, col. I, núm. 1. Salvador, Brasil, p. 1-46.

SEPÚLVEDA, María Magdalena. The nature of the obligations under the international covenant on economic, social and cultural rights. Antwerp: Intersentia, 2003.

SHUE, Henry. Basic rights: subsistence, affluence, and U.S. foreign policy. New Jersey: Princeton University Press, 1980.

SOHN, Louis B.; BUERGENTHAL, Thomas. International protection of human rights. Indianapolis: Bobbs-Merrill, 1973.

STRECK, Lenio Luiz. Jurisdição constitucional e hermenêutica. 2. ed. Rio de Janeiro: Forense, 2004.

TRINDADE, Antônio Augusto Cançado. O legado da Declaração Universal e o futuro da proteção internacional dos direitos humanos. In: AMARAL JR., Alberto do; PERRONE-MOISÉS, Cláudia (Org.). O Cinqüentenário da Declaração Universal dos Direitos do Homem. São Paulo: Editora da Universidade de São Paulo, 1999, p. 13-54. 
A proteção internacional dos direitos humanos: fundamentos jurídicos e instrumentos básicos. São Paulo: Saraiva, 1991.

VALTICOS, Nicolas. Normas internacionales del trabajo y derechos humanos: ¿Cómo estamos en vísperas del año 2000? Revista Internacional del Trabajo, 1998, v. 177, n. 2, p. 153-166.

YOUNG, Katherine G. Constituing economic and social rights. Oxford: Oxford University Press, 2012.

\title{
SOCIAL AND LABOUR RIGHTS AS HUMAN RIGHTS: AFFIRMATION, RECOGNITION AND OBSTACLES TO THEIR ENFORCEABILITY INTO THE BRAZILIAN LEGAL SYSTEM
}

\begin{abstract}
This article aims to reflect about the obstacles to the full enforcement of social human rights in the Brazilian legal system, with special emphasis on labor rights. The research approach rests on the premise bases that the dignity of the human person is the guiding principle of international and national legal regulations about labor. In this sense, it is true that the Constitution of the Federative Republic of Brazil, from 1988, consolidated this idea, recognizing a true hard core of labor rights for achieving a minimum level protection to guarantee dignity for the workers. Therefore, the State is obliged to effectively search the materialization of that minimum conditions that enable workers to achieve a decent standard of living. Therefore, as it will be examined throughout this article, legal justifications that have been made in the field of the Judiciary to impede the full scope of its enforcement should be considered illegitimate, because of the manifested constitutional provision of its recognition and the transcendence significance of the principle of human dignity in the Brazilian legal system.
\end{abstract}

\section{KEYWORDS}

Human rights. Labor rights. Dignity. Enforcement. Labor. 